\title{
Imagem e reafirmação da identidade: a fotografia como linguagem na Antropologia
}

\author{
Carlos de Matos Bandeira Junior ${ }^{1}$
}

Artigo recebido em: 13 de novembro de 2017. Artigo aprovado em: 15 de novembro de 2017.

A Antropologia utilizou-se dos recursos de registros das imagens desde que estes estiveram disponíveis (CAIUBY, 1198). O antropólogo Achutti (2004) lembra que a fotografia e a antropologia nasceram em tempos próximos e com preocupações parecidas, ambas dedicaram atenção à compreensão da vida do homem e as características do meio social e cultural. Não à toa, importantes pesquisadores incorporaram a seus trabalhos a fotografia como instrumento descritivo, Malinowski, em Argonautas do Pacífico Ocidental (1914), traz, nesta obra, denso acervo fotográfico da experiência de pesquisa junto aos Trobriandeses.

No entanto, apesar da frequência do uso da imagem nos trabalhos antropológicos, esta foi utilizada como simples recurso de ilustração ao texto escrito e tratada com reticencia como linguagem dentro do campo da Antropologia por ser entendida como impregnada de subjetividades e, também, pela pressuposição da academia na crença da superioridade objetiva do texto em relação aos recursos imagéticos e não textuais (CAIUBY, 1998, p. 115).

Essa perspectiva altera-se com a própria desconstrução da objetividade perseguida pela Antropologia no seu modo de produzir conhecimento. A etnografia, sistematizada por Malinowski, sai do lugar de elaborar a história do outro ao ponto de reconfigurarse na relação com o outro, num encontro de subjetividades, revertendo a autoridade etnográfica e científica, concebendo esse outro como sujeito também capaz de produzir representações de si e do outro (CLIFFORD,2002).

As rupturas no modo de pensar o conhecimento antropológico permitiram à fotografia e outras linguagens imagéticas a adquirirem outro corpus de importância no

\footnotetext{
${ }^{1}$ Mestrando do Programa de Pós-graduação em Ciências da Sociedade, da Universidade Federal do Oeste do Pará (PPGCS/UFOPA); Graduado em Comunicação Social com habilitação em Publicidade e Propaganda pelas Faculdades Integradas do Tapajós - FIT; Graduando em Antropologia pela Universidade Federal do Oeste do Pará (UFOPA). Email: carlosjrfotografo@gmail.com
} 
campo da disciplina. Abriu-se um terreno específico para pensar os significados culturais gerados pela imagem e como as imagens são produzidas e percebidas socialmente (RIBEIRO, 2014, p.238), superando de uma vez por todas a hierarquia entre texto e imagem.

A respeito deste aspecto, Sylvia Caiuby Novaes (1998, p.116) compreende tanto as imagens quanto os textos como artefatos culturais e que a produção de filmes, fotografias pode acrescentar outras dimensões a interpretação da história cultural dos grupos sociais, possibilitando aprofundamento na compreensão do universo simbólico. Esta autora, aponta que certos fenômenos culturais "só podem explicar no plano das formas sensíveis o seu significado mais profundo" e que o uso de imagens para narrar tais fenômenos consegue aproximar com mais eficácia a um dos principais objetivos da Antropologia que é a de produção de uma comunicação intercultural.

Neste sentido, trago um conjunto de imagens como narração fotoetnográfica ${ }^{2}$ das ações, mobilizações e lutas protagonizadas pelo movimento social indígena do Baixo Tapajós, ocorridos na cidade de Santarém, entre os anos de 2014 e 2016, como forma de produzir uma comunicação intercultural amparada nas possibilidades da linguagem da imagem fotográfica.

\footnotetext{
${ }^{2}$ Método de narrativa em que deve se apresentar na forma de uma série de fotos que estejam relacionadas entre si e componham uma sequencia de informações visuais. Série de fotos que deve oferecer apenas ao olhar, sem nenhum texto intercalado a desviar a atenção do leitor espectador. Essa precaução não impede que certas informações escritas possam ter sido anteriormente dadas aqueles que vão mergulhar na narrativa visual (ACHUTTI, 2004, p.109).
} 


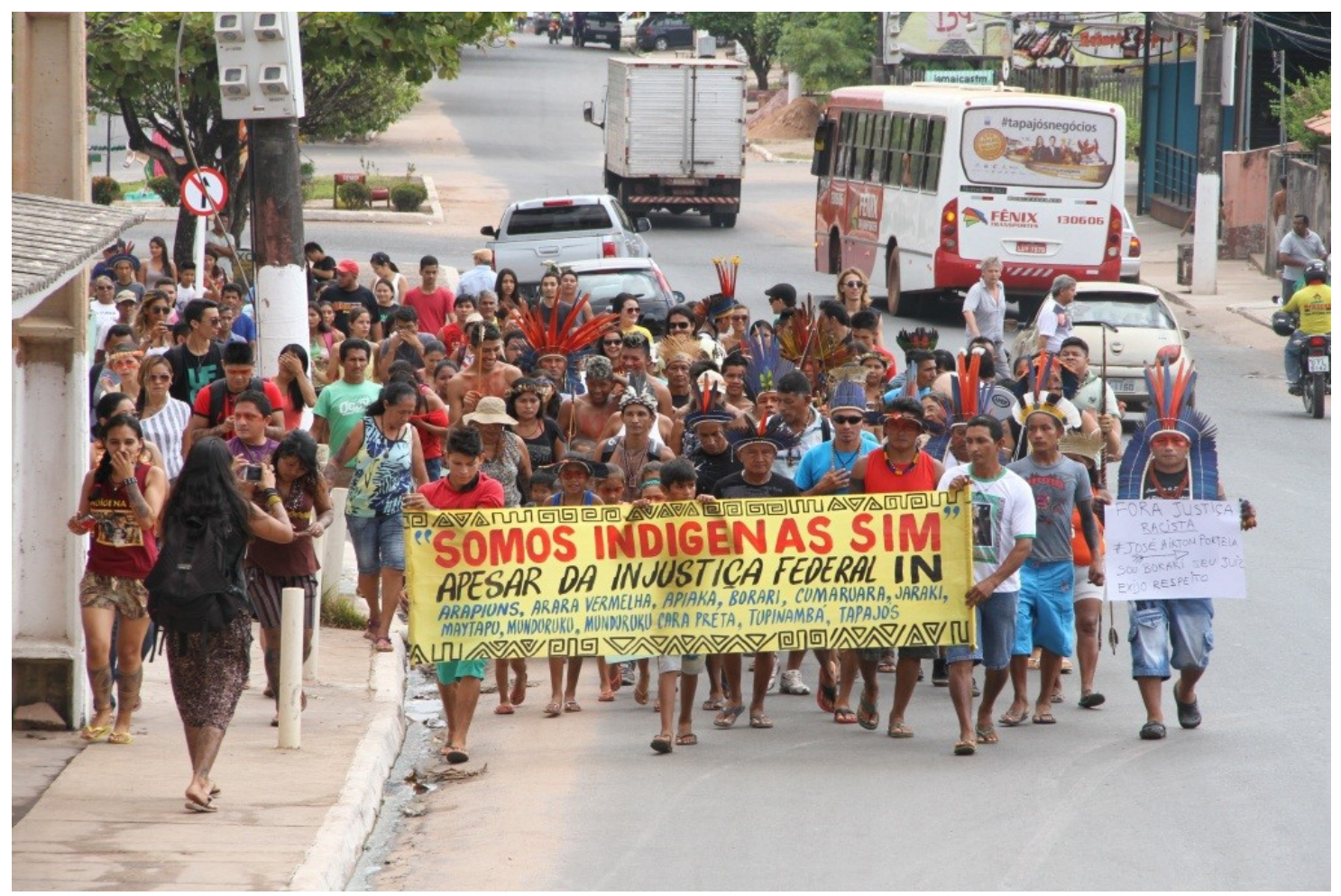

Figura 1.

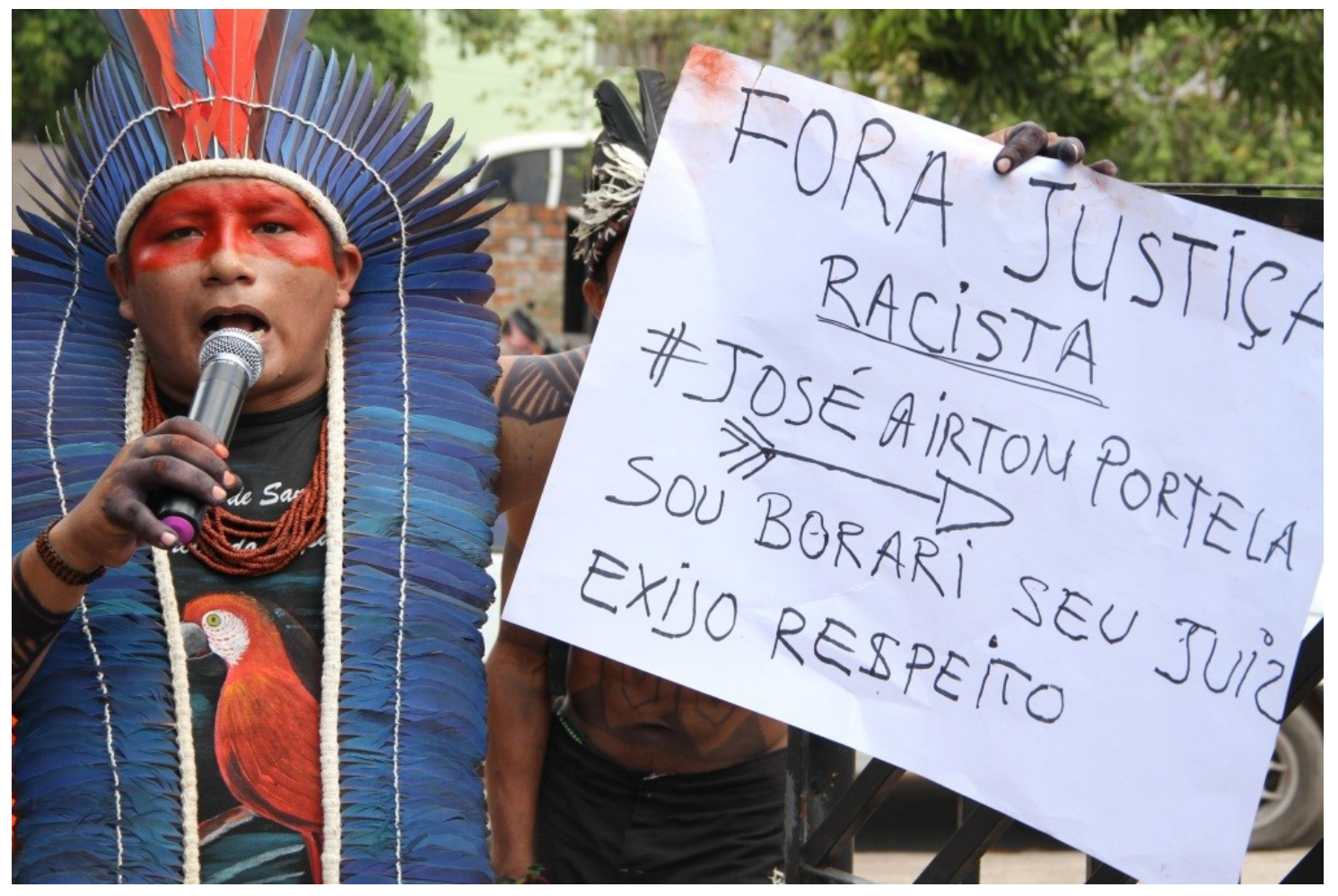

Figura 2. 


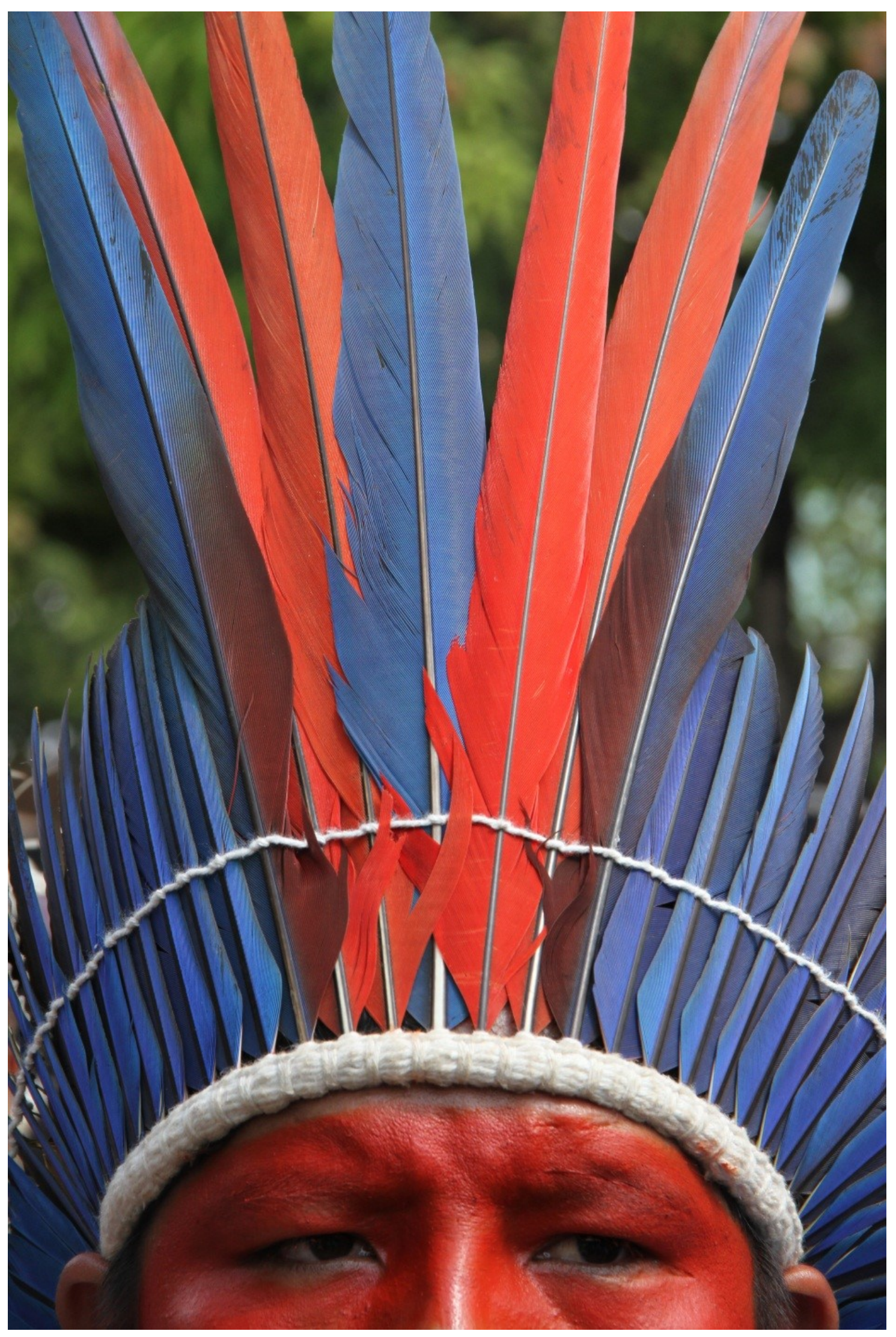

Figura 3. 


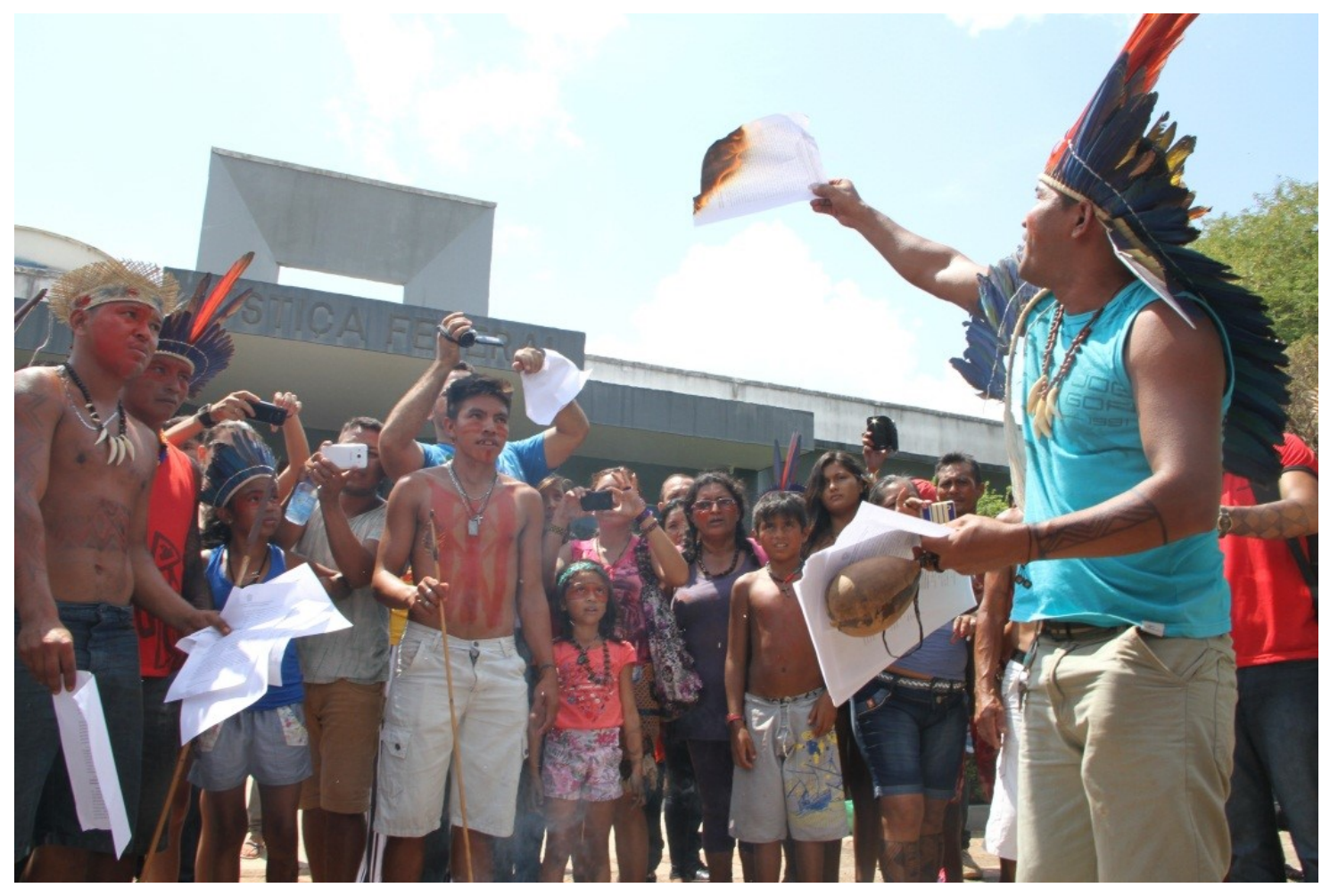

Figura 4.

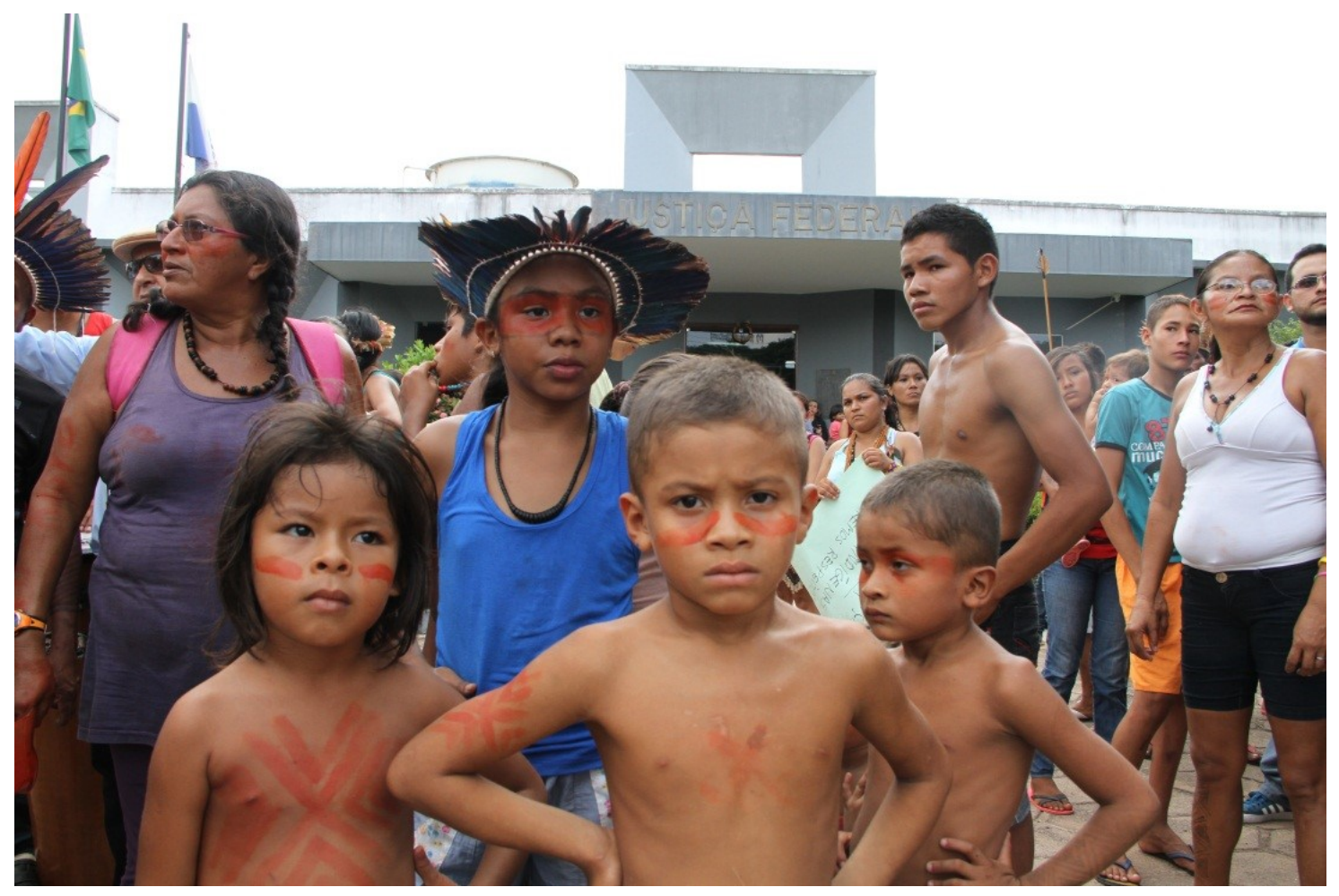

Figura 5. 


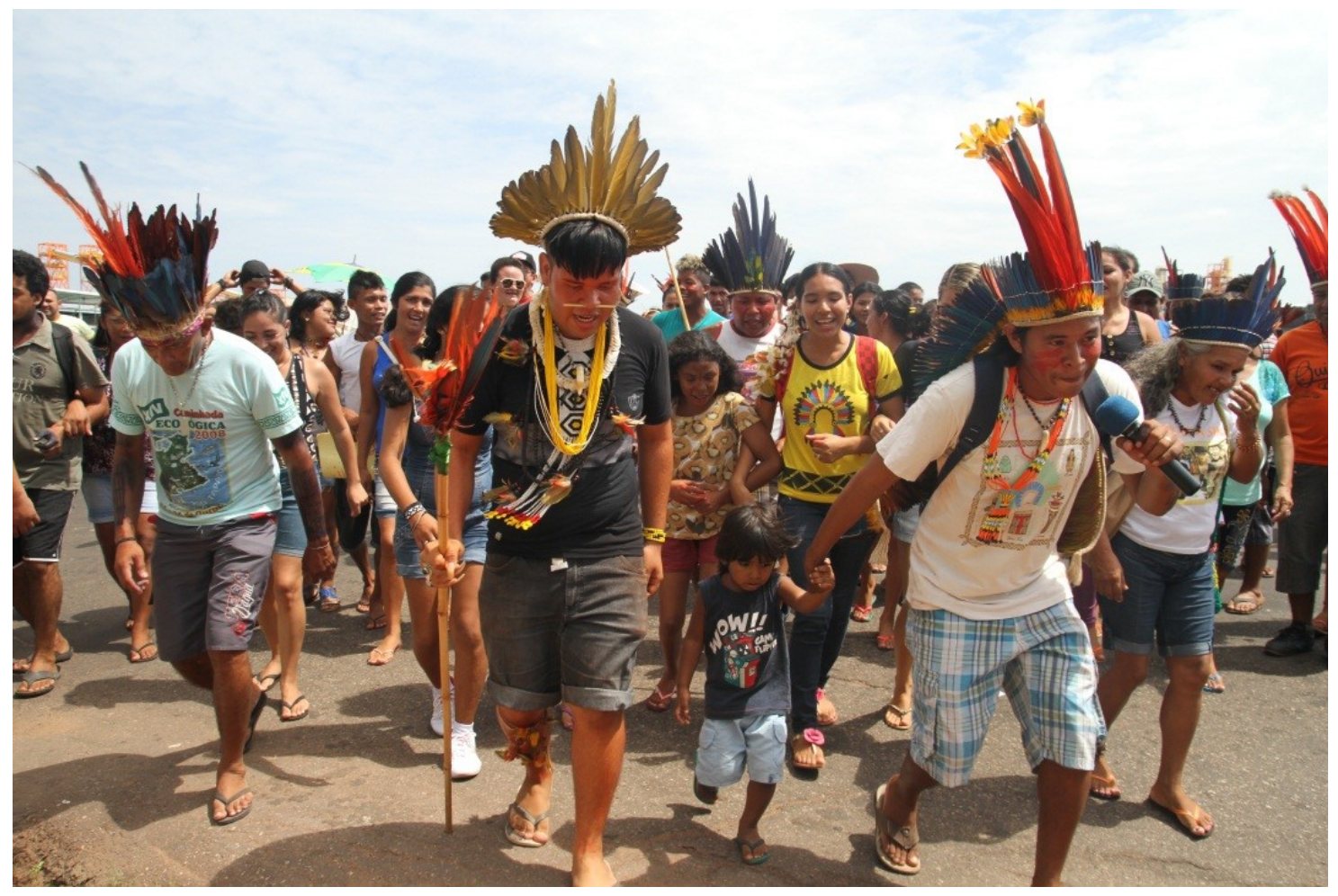

Figura 6.

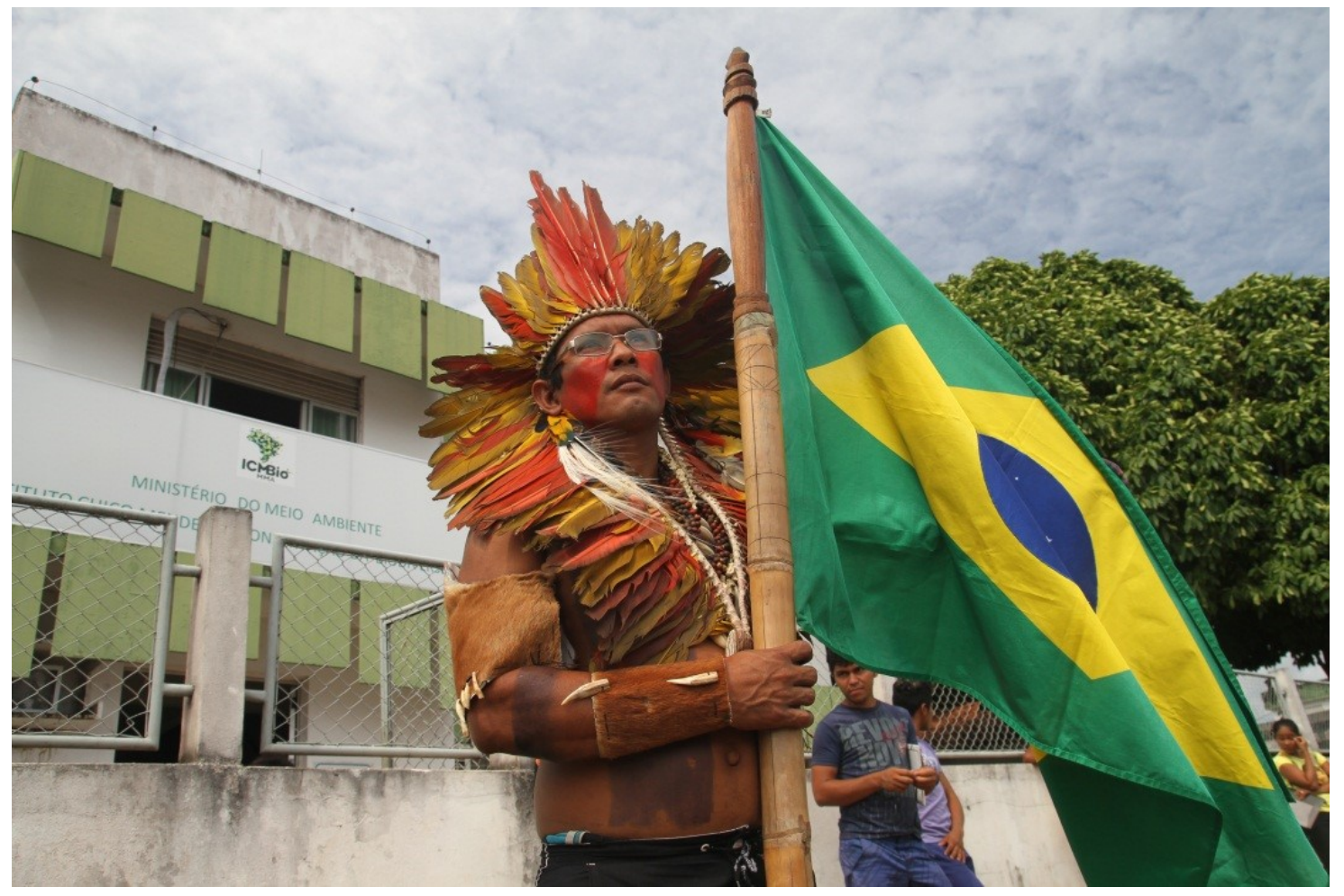

Figura 7. 


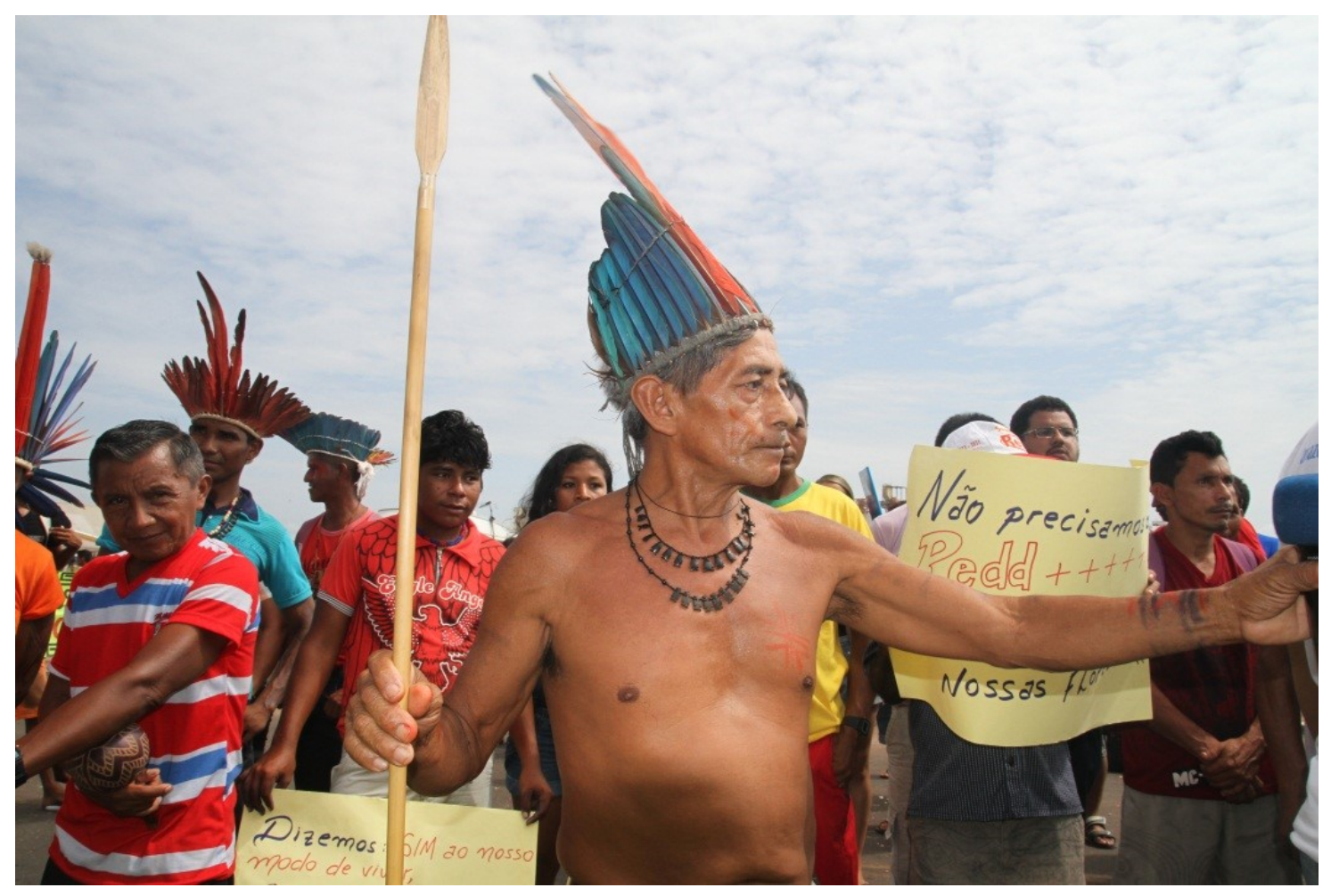

Figura 8.

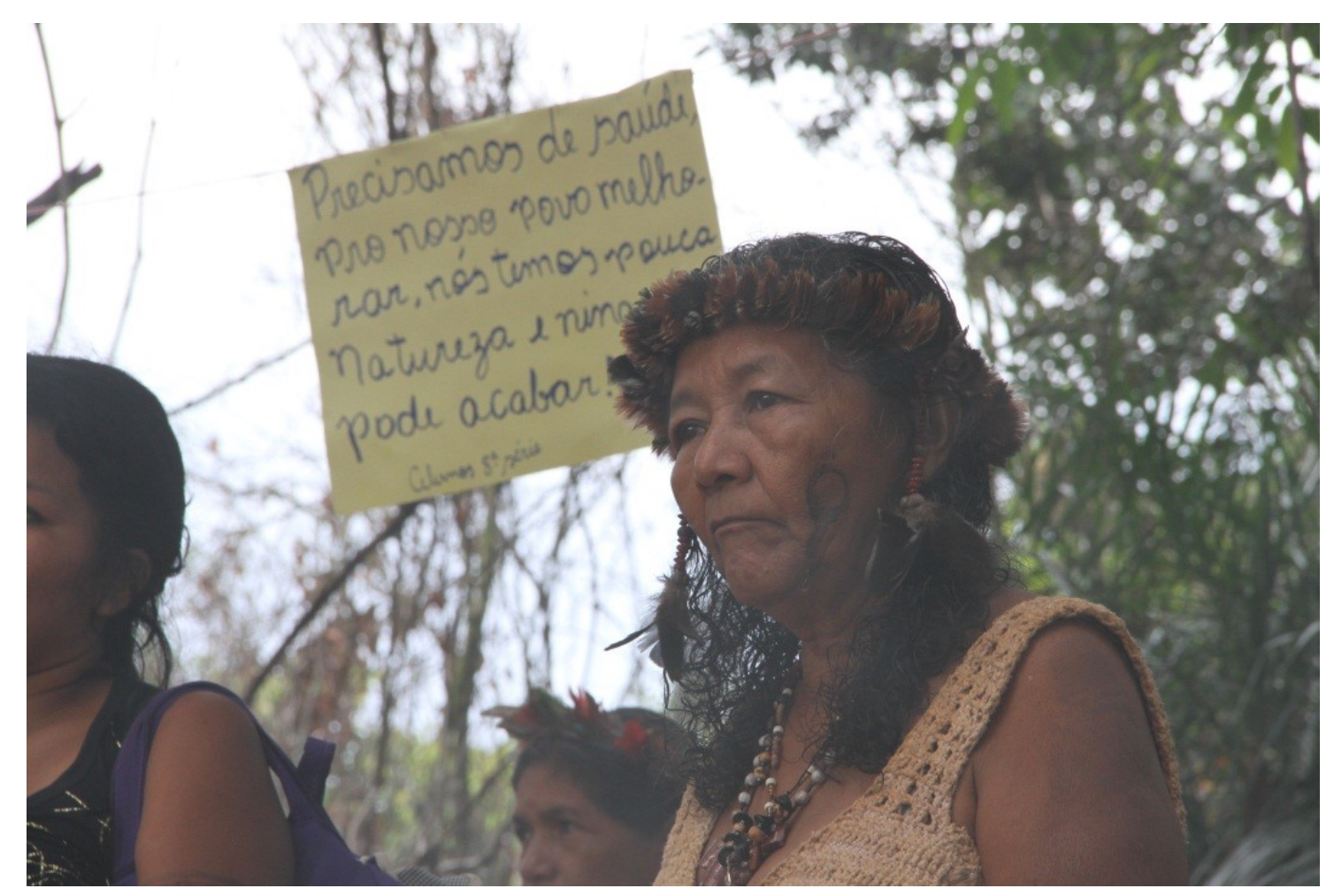

Figura 9. 


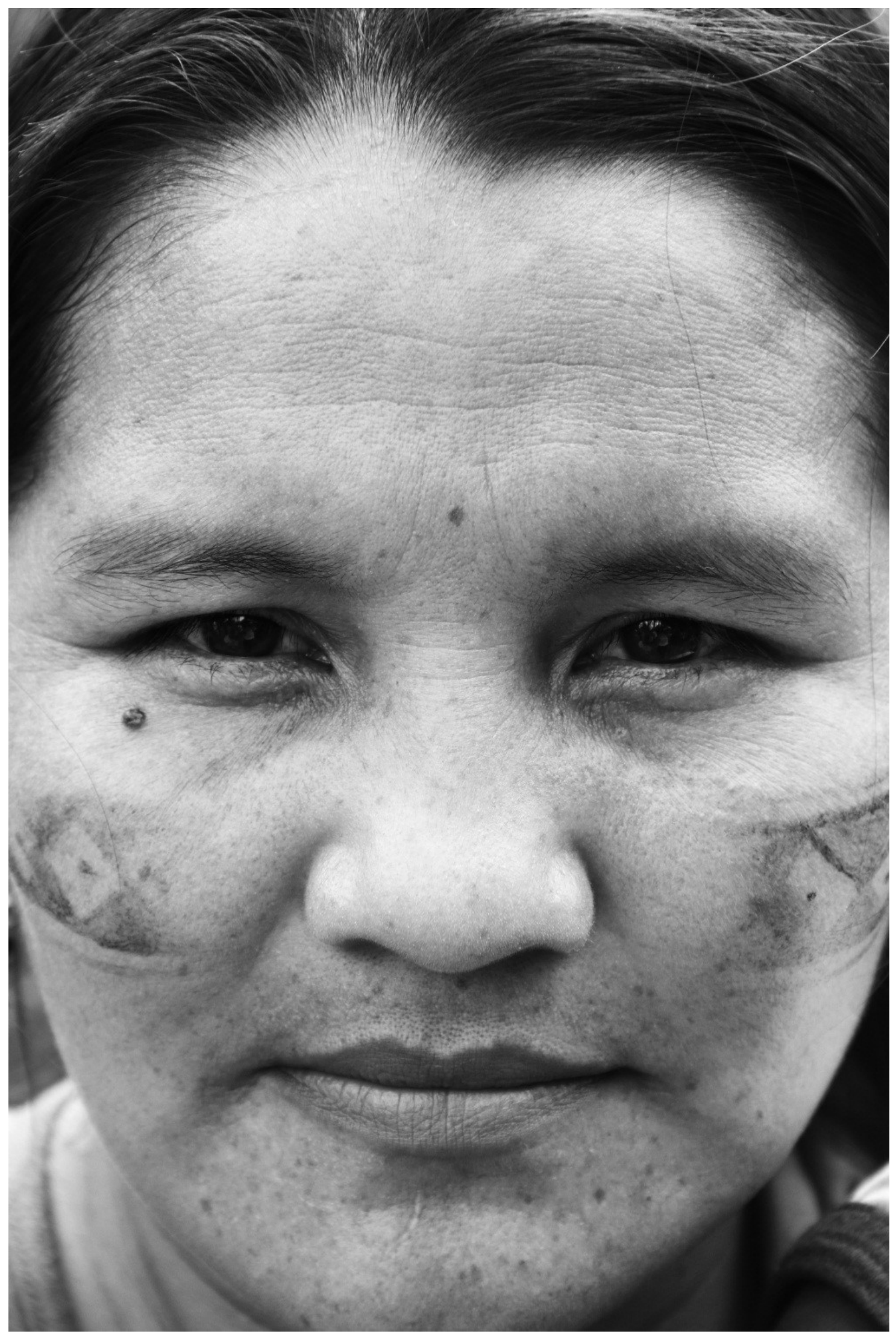

Figura 10. 


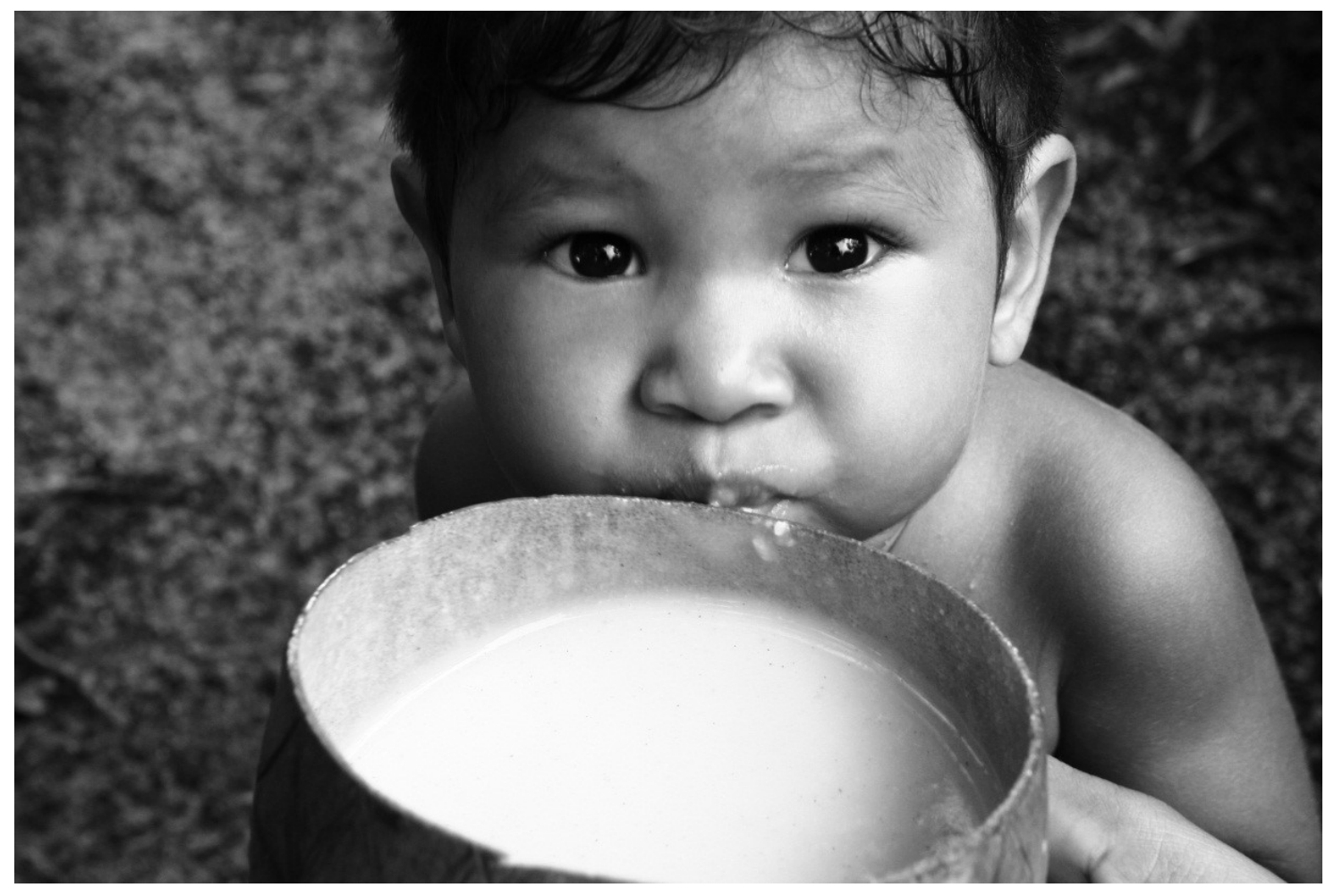

Figura 11. 


\section{Referências}

ACHUTTI, Luiz Eduardo Robinson. Fotoetnografia da Biblioteca Jardim. Porto Alegre: Editora da UFRGS/Tomo Editorial, 2004.

CAIUBY NOVAES, Sylvia. O uso da imagem na Antropologia. O fotográfico. Org. Etienne Samain ? São Paulo: Hucitec, 1998.

. Imagem em foco nas Ciências Sociais. Escrituras da Imagem/

Sylvia Caiuby Novaes [et. al.]. (Orgs) - São Paulo: Fapesp: Editora da Universidade de São Paulo, 2004.

CLIFFORD, James. A experiência etnográfica: antropologia e literatura no século XX/ James Clifford; organizado por José Reginaldo Santos Gonçalves. 2. ed. Rio de Janeiro: Editora UFRJ, 2002.

RIBEIRO, Jose da Silva. Vinte e cinco anos de antropologia visual na Universidade Aberta de Portugal. IN: FERRAZ, Ana Lúcia Camargo; MENDONÇA, João Martinho de (Orgs.). Antropologia visual: perspectivas de ensino e pesquisa. Brasília- DF: ABA, 2014. 